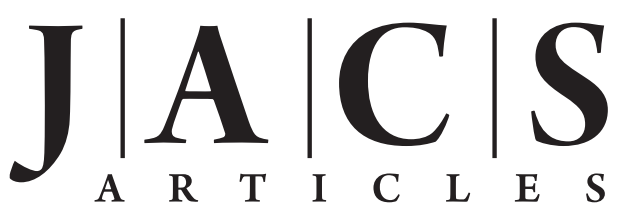

Published on Web 03/18/2010

\title{
Selective Manipulation of ICT and PET Processes in Styryl-Bodipy Derivatives: Applications in Molecular Logic and Fluorescence Sensing of Metal lons
}

\author{
O. Altan Bozdemir, ${ }^{\dagger}$ Ruslan Guliyev, ${ }^{\dagger}$ Onur Buyukcakir, $^{\dagger}$ Sencer Selcuk, ${ }^{\ddagger}$ \\ Safacan Kolemen, ${ }^{\ddagger}$ Gulcihan Gulseren, ${ }^{\ddagger}$ Tugrul Nalbantoglu, ${ }^{\ddagger}$ Hande Boyaci, ${ }^{\ddagger}$ and \\ Engin U. Akkaya*,t,‡ \\ UNAM-Institute of Materials Science and Nanotechnology, Bilkent University, 06800 Ankara, Turkey \\ and Department of Chemistry, Bilkent University, 06800 Ankara, Turkey
}

Received January 29, 2010; E-mail: eua@fen.bilkent.edu.tr

\begin{abstract}
Remarkably versatile chemistry of Bodipy dyes allows the design and straightforward synthesis of multivalent-multitopic derivatives, which, with judicious selection of metal ion-ligand pairs based on known affinities, affords control and manipulation of photoinduced electron transfer and internal charge transfer processes as desired. We have demonstrated that metal ions acting as modulators (or inputs, in digital design parlance) can generate absorbance changes in accordance with the operation of a halfadder. In addition, an AND logic gate in the emission mode was delivered using a different binucleating arrangement of ligands. A molecular equivalent of a three-input AND logic gate was also obtained exploiting differential binding affinities of metal ions for different ligands. The results suggest that different metal ions can be used as nonannihilating inputs, selectively targeting various ligands incorporated within a single fluorophore, and with careful design, diverse photophysical processes can be selectively modulated, resulting in a range of signals, useful in molecular logic design, and offering an enticing potential for multianalyte chemosensors.
\end{abstract}

\section{Introduction}

Molecular logic research today is built on an initial recognition by de Silva ${ }^{1}$ that fluorescence signals obtained in response to cations could be considered to be analogous to the digital responses in electronic logic gates. Molecules can undergo changes in the ground or excited states, in response to modulators which can be other molecules, ions, or light of a certain wavelength. In most cases, these changes could then be signaled by changes in the emission intensity, or wavelength, and can be related to the operation of logic gates, via the familiar Boolean logic. ${ }^{2}$ In addition, it has become apparent that logic gate design using molecules may not necessarily be subject to the same limitations as the silicon-based analogues. One can design a single molecule which can simultaneously behave as two (or more) distinct logic gates, depending on the exact choice or definition of outputs. ${ }^{3}$ On the other hand, while functional

UNAM-Institute of Materials Science and Nanotechnology.

$\doteqdot$ Department of Chemistry.

(1) de Silva, A. P.; Gunaratne, H. Q. N.; McCoy, C. P. Nature 1993, $364,42-44$

(2) Hayes, J. P. Introduction To Digital Logic Design; Addison-Wesley Publishing Company: Reading, MA, 1993.

(3) (a) Adleman, L. M. Science 1994, 266, 1021-1024. (b) de Silva, A. P.; McClenaghan, N. D. Chem.-Eur. J. 2004, 10, 574-586. (c) Lee, T. H.; Gonzalez, J. I.; Zheng, J.; Dickson, R. M. Acc. Chem. Res. 2005, 38 , 534-541. (d) Pischel, U. Angew. Chem., Int. Ed. 2007, 46, 40264040. (e) de Silva, A. P.; Uchiyama, S. Nat. Nanotechnol. 2007, 2 , 399-410. (f) Szacilowski, K. Chem. Rev. 2008, 108, 3481-3548. integration is possible within a single molecule, ${ }^{4}$ at least partly because of input-output heterogeneity, integration of logic gates to implement more complex functions is far from being straightforward. Nevertheless, molecular logic gates represent

(4) de Silva, A. P.; Dixon, I. M.; Gunaratne, H. Q. N.; Gunnlaugsson, T.; Maxwell, P. R. S.; Rice, T. E. J. Am. Chem. Soc. 1999, 121, 13931394.

(5) (a) Credi, A.; Balzani, V.; Langford, S. J.; Stoddart, J. F. J. J. Am. Chem. Soc. 1997, 119, 2679-2681. (b) de Silva, A. P.; McClenaghan, N. D. J. Am. Chem. Soc. 2000, 122, 3965-3966. (c) Saghatelian, A.; Völcker, N. H.; Guckian, K. M.; Lin, V. S.-Y.; Ghadiri, M. Z. J. Am. Chem. Soc. 2003, 125, 346-347. (d) Langford, S. J.; Yann, T. J. Am. Chem. Soc. 2003, 125, 11198-11199. (e) Margulies, D.; Melman, G.; Felder, C. E.; Arrad-Yellin, R.; Shanzer, A. J. Am. Chem. Soc. 2004, 126, 15400-15401. (f) Amir, R. J.; Popkov, M.; Lerner, R. A.; Barbos, C. F.; Shabat, D. Angew. Chem., Int. Ed. 2005, 44, 4378-4381. (g) Margulies, D.; Melman, G.; Shanzer, A. Nat. Mater. 2005, 4, 768771. (h) de Silva, A. P.; James, M. R.; McKinney, B. O. F.; Pears, P. A.; Weir, S. M. Nat. Mater. 2006, 5, 787-790. (i) Margulies, D.; Melman, G.; Shanzer, A. J. Am. Chem. Soc. 2006, 128, 4865-4871. (j) Magri, D. C.; Brown, G. J.; McClean, G. D.; de Silva, A. P. J. Am. Chem. Soc. 2006, 128, 4950-4951. (k) Andreasson, J.; Straight, S. D.; Bandyopadhyay, S.; Mitchell, R. H.; Moore, T. A.; Moore, A. L.; Gust, D. Angew. Chem., Int. Ed. 2007, 46, 958-961. (1) Margulies, D.; Felder, C. E.; Melman, G.; Shanzer, A.J. Am. Chem. Soc. 2007, 129, 347-354. (m) Rinaudo, K.; Bleris, L.; Maddemsetti, R.; Subramanian, S.; Weiss, R.; Benenson, Y. Nat. Biotechnol. 2007, 25, 795-801. (n) Frezza, B. M.; Cockroft, S. L.; Ghadiri, M. R. J. Am. Chem. Soc. 2007, 129, 14875-14879. (o) Kou, S.; Lee, H. N.; Van Noort, D.; Swamy, K. M. K.; Kim, S. H.; Soh, J. H.; Lee, K.-M.; Nam, S.-W.; Yoon, J.; Park, S. Angew. Chem., Int. Ed. 2008, 47, 872-876. (p) Motornov, M.; Zhou, J.; Pita, M.; Gopishetty, V.; Tokarev, I.; Katz, E.; Minko, S. Nano Lett. 2008, 8, 2993-2998. (q) Win, M. N.; Smolke, C. D. Science 2008, 322, 456. (r) Amelia, M.; Baroncini, M.; Credi, A. Angew. Chem., Int. Ed. 2008, 47, 6240-6243. (s) Andreasson, J.; Pischel, U. Chem. Soc. Rev. 2010, 39, 174-188. 
a true bottom-up approach for information processing at the molecular level. The strongest aspect of molecular logic gates is the fresh new look, which provides a novel mental platform to build new ideas. More recently, logic gate research is perhaps being redefined as of late, with an eye on the applications, ${ }^{5}$ the most interesting targets being the small spaces such as the inside of a cell, where silicon-based analogues are not expected to get in. ${ }^{6}$ Among the possible signal modalities, changes in absorption or emission spectra are the most common ones. The photoinduced electron transfer (PET) process was particularly useful in this regard, as the signal, depending on the special circumstances, was either an "on-off" or "off-on" type, ${ }^{7}$ resulting in a well-defined "digital" response. PET produces very sharp changes in the signal intensity, while keeping the emission wavelength unchanged. ${ }^{8}$ Internal charge transfer (ICT, a.k.a., PCT: photoinduced charge transfer $)^{9,10}$ on the other hand can be modulated in such a way to generate changes in the absorption or emission wavelengths, which proved to be very useful for superposed logic gates, sometimes referred to as wavelength-reconfigurable logic gates. ${ }^{11}$ Our first contribution in molecular logic gates in the year $2000^{9 \mathrm{a}}$ broke the near monopoly of PET processes in logic gate design. Molecular interactions, including cation binding, were known to produce shifts in the absorption and emission peaks, but it was this article which first presented the explicit use of spectral shifts to harvest two distinct superposed logic gates out of a single molecular recognition phenomenon. This was simply done by choosing two different observation wavelengths, i.e. two different chan-

(6) (a) Balzani, V.; Credi, A.; Venturi, M. Proc. Natl. Acad. Sci. U.S.A. 2002, 99, 4814-4817. (b) Coskun, A.; Deniz, E.; Akkaya, E. U. Org. Lett. 2005, 7, 5187-5189. (c) Chen, X.; Wang, Y. F.; Liu, Q.; Zhang, Z. Z.; Fan, C. H.; He, L. Angew. Chem., Int. Ed. 2006, 45, 17591762. (d) Miyoshi, D.; Inouo, M.; Sugimoto, N. Angew. Chem., Int. Ed. 2006, 45, 7716-7719. (e) Andréasson, J.; Straight, S. D.; Kodis, G.; Park, C.-D.; Hambourger, G.; Gervaldo, M.; Albinsson, B.; Moore, T. A.; Moore, A. L.; Gust, D. J. Am. Chem. Soc. 2006, 128, 1625916265. (f) Magri, D. C.; Brown, G. J.; McClean, G. D.; de Silva, A. P. J. Am. Chem. Soc. 2006, 128, 4950-4951. (g) de Silva, A. P.; de Silva, S. S. K.; Goonesekera, N. C. W.; Gunaratne, H. Q. N.; Lnch, P. L. M.; Nesbitt, K. R.; Patuwathavithana, S. T.; Ramyalal, N. L. D. S. J. Am. Chem. Soc. 2007, 129, 3050-3051. (h) Motornov, M. M.; Zhou, J.; Pita, M.; Gopishetty, V.; Tokarev, I.; Katz, E.; Minko, S. Nano Lett. 2008, 8, 2993-2997. (i) Komatsu, H.; Matsumoto, S.; Tamaru, S.-I.; Kaneko, K.; Ikeda, M.; Hamachi, I. J. Am. Chem. Soc. 2009, 131, 5580-5585. (j) Wang, Z.; Palacios, M. A.; Zyryanov, G.; Anzenbacher, P., Jr. Chem.-Eur. J. 2008, 14, 8540-8546. (k) Tam, T. K.; Strack, G.; Pita, M.; Katz, E. J. Am. Chem. Soc. 2009, 131 11670-11671. (1) Feng, X.; Duan, X.; Liu, L.; Feng, F.; Wang, S.; Li, Y.; Zhu, D. Angew. Chem., Int. Ed. 2009, 48, 5316-5321. (m) Chang, J. W.; Yoon, S.-J.; Lim, S.-J.; An, B.-K.; Park, S. Y. Angew. Chem., Int. Ed. 2009, 48, 7030-7034. (n) Shlyahovsky, B.; Li, Y.; Lioubashevski, O.; Elbaz, J.; Willner, I. ACS Nano 2009, 3, 1831-1843. (o) Kumar, M.; Dhir, A.; Bhalla, V. Org. Lett. 2009, 11, 2567-2570. (p) Ozlem, S.; Akkaya, E. U. J. Am. Chem. Soc. 2009, 131, 48-49.

(7) (a) de Silva, A. P.; McClenaghan, N. D. J. Am. Chem. Soc. 2000, 122, 3965-3966. (b) Kaur, N.; Singh, N.; Cairns, D.; Callan, J. F. Org. Lett. 2009, 11, 2229-2232.

(8) (a) Bissell, R. A.; de Silva, A. P.; Gunaratne, H. Q. N.; Lynch, P. L. M.; Maguire, G. E. M.; Sandanayake, K. R. A. S. Chem. Soc. Rev. 1992, 21, 187-195. (b) Bissell, R. A.; de Silva, A. P.; Gunaratne, H. Q. N.; Lynch, P. L. M.; Maguire, G. E. M.; McCoy, C. P.; Sandanayake, K. R. A. S. Top. Curr. Chem. 1993, 168, 228-264.

(9) (a) Baytekin, H. T.; Akkaya, E. U. Org. Lett. 2000, 2, 1725-1727. (b) de Silva, A. P.; McClenaghan, N. D. Chem.-Eur. J. 2002, 8, 49354945.

(10) (a) Valeur, B.; Leray, I. Coord. Chem. Rev. 2000, 205, 3-40. (b) Valeur, B.; Leray, I. Inorg. Chem. Acta 2007, 360, 765-774. (c) Yuan, M.; Zhou, W.; Liu, X.; Zhu, M.; Li, J.; Yin, X.; Zheng, H.; Zuo, Z.; Ouyang, C.; Liu, H.; Li, Y.; Zhu, D. J. Org. Chem. 2008, 73, 50085014.

(11) Remon, P.; Ferreira, R.; Montenegro, J. M.; Suau, R.; Perez-Inestrosa, E.; Pischel, U. ChemPhysChem 2009, 10, 2004-2007. nels. Naturally, by finer adjustment of the parameters, more than two logic gates can be obtained. ICT processes are, of course, highly desirable for this kind of design, as very large spectral shifts are the norm rather than exception in ICT fluorophores with electron donor (or acceptor) ligands as integral parts of the $\pi$-systems. To increase signal diversity, it is possible to include both PET and ICT processes on a single fluorophore. ${ }^{9 b}$ We have demonstrated an example of that approach a few years ago, ${ }^{6 \mathrm{~b}}$ and it is a very straightforward path to a molecular "halfsubtractor" once the inputs were chosen to be self-annihilating. In that article, we also restated the obvious, which is the fact that the assignment of " 1 " to a high signal and " 0 " to a low signal is arbitrary in both molecular and silicon-based information processing. The reverse is equally acceptable and known as "negative logic" in electronics. Annihilating inputs on the other hand is quite convenient, when one needs to produce an XOR gate, but the use of such inputs (like a strong acid and strong base) in logic gates would have quite a limited value, with any consideration of practicality ("reset" cabability is a notable exception ${ }^{5 s}$ ). Especially in aqueous solutions, $\mathrm{H}^{+}$and $\mathrm{OH}^{-}$are not independent variables. It must be self-evident that the inputs in a logic gate have to be independent variables. With that kind of a perspective, it made a lot of sense for us to find new designs for simple logic elements, with a potential for integration and independently variable inputs. The key may be selectivity. Metal ions, with their inherent selectivities for ligands, have been used as chemical inputs in many molecular logic gates. Metal ions are Lewis acids, and it is possible to make use of them as nonselective agents, just like hydrogen ions. However, accumulated knowledge of ligand design, ${ }^{10 a}$ and available quantitative data on metal-ligand affinities, should allow one to propose selective interactions in a mixture of metal ions with a molecule containing multiple ligating sites. ${ }^{12}$ Selective targeting of different modulation sites within a fluorophore could be important for practical sensing applications as well.

The fluoroionophores of choice in this work is Bodipy-derived (Figure 1). ${ }^{13}$ Bodipy dyes have become a rising star of fluorophores in the fluorescent chemosensor community ${ }^{14}$ due to their remarkable properties such as a high quantum yield and large extinction coefficients. But more importantly, these dyes are open to derivatization in a multitude of ways through recently expanding "Bodipy chemistry". ${ }^{15}$ Part of this versatile chemistry allowed us to design new Bodipy-based fluorescent

(12) de Silva, A. P.; Gunarante, H. Q. N.; Gunnlaugsson, T.; Huxley, A. J. M.; McCoy, C. P.; Rademacher, J. T.; Rice, T. E. Chem. Rev. 1997, 97, 1515-1566.

(13) (a) Loudet, A.; Burgess, K. Chem. Rev. 2007, 107, 4891-4932. (b) Ziessel, R.; Ulrich, G.; Harriman, A. New J. Chem. 2007, 31, 496501. (c) Ulrich, G.; Ziessel, R.; Harriman, A. Angew. Chem., Int. Ed. 2008, 47, 1184-1201.

(14) (a) Rurack, K.; Kollmansberger, M.; Resch-Genger, U.; Daub, J. J. Am. Chem. Soc. 2000, 122, 968-969. (b) Coskun, A.; Akkaya, E. U. J. Am. Chem. Soc. 2005, 127, 10464-10465. (c) Coskun, A.; Akkaya, E. U. J. Am. Chem. Soc. 2006, 128, 14474-14475. (d) Sunahara, H.; Urano, Y.; Kojima, H.; Nagano, T. J. Am. Chem. Soc. 2007, 129, 5597-5604. (e) Yuan, M.; Li, Y.; Li, J.; Liu, X.; Lv, J.; Xu, J.; Liu, H.; Wang, S.; Zhu, D. Org. Lett. 2007, 9, 2313-2316. (f) Atilgan, S.; Ozdemir, T.; Akkaya, E. U. Org. Lett. 2008, 10, 4065-4067. (g) Hudnall, T. W.; Gabbai, F. P. Chem. Commun. 2008, 4596-4598. (h) Qi, X.; Kim, S. K.; Han, S. J.; Xu, L.; Jee, A. Y.; Kim, H. N.; Lee, C.; Kim, Y.; Lee, M.; Kim, S. J.; Yoon, J. Tetrahedron Lett. 2008, 49, 261-264. (i) Kennedy, D. P.; Kormos, C. M.; Burdette, S. C. J. Am. Chem. Soc. 2009, 131, 8578-8586. (j) Guliyev, R.; Coskun, A.; Akkaya, E. U. J. Am. Chem. Soc. 2009, 131, 9007-9013. (k) Diring, S.; Puntoriero, F.; Nastasi, F.; Campagna, S.; Ziessel, R. J. Am. Chem. Soc. 2009, 131, 6108-6109. 


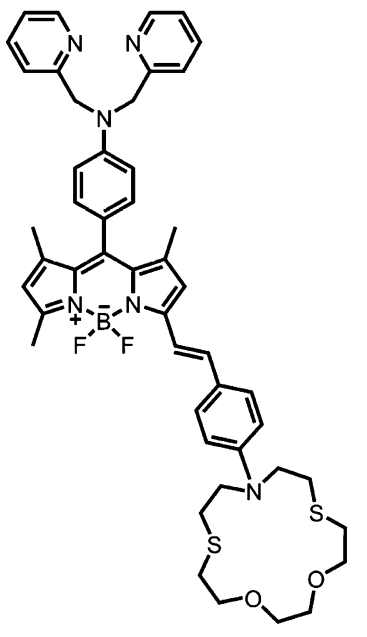

2

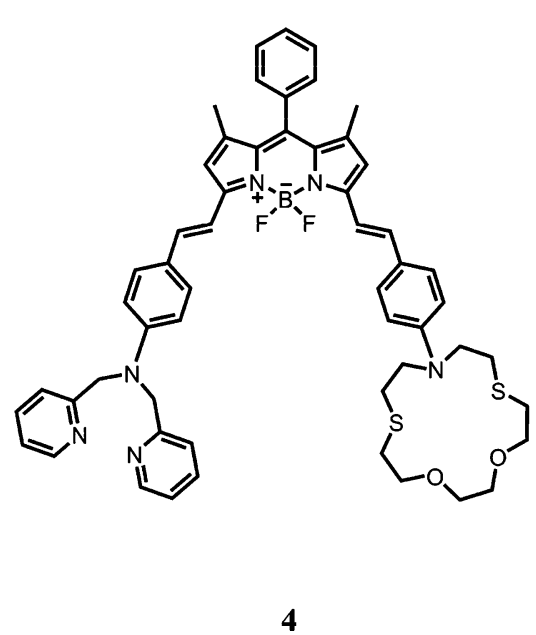

4

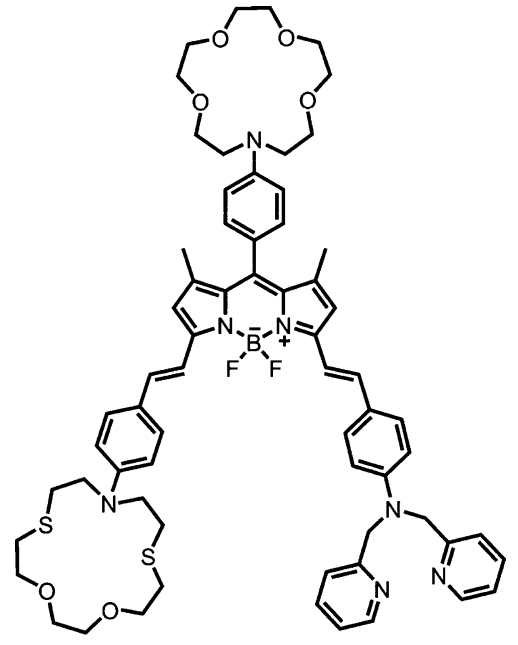

7

Figure 1. Target structures for two-input AND logic 2, Half-Adder 4, and three-input AND logic 7.

molecules with different ligands attached at locations where the modulation of ICT and PET processes can be achieved independently. This is not an easy synthetic task for most other fluorophores. But, with Bodipy dyes, it is just a couple of well coordinated sequence of transformations.

Synthesis. We targeted three different styryl-Bodipy derivatives 2, 4, and 7 (Figure 1). In designing these compounds, we kept in mind that the meso-substituents are more likely to interfere with the excited state processes only, partly because of the orthogonal arrangement of the meso-(8)-phenyl moiety under the steric influence of the neighboring $(1,7)$ methyl groups, and partly due to the fact that, in the HOMO of the Bodipy chromophore, the $\mathrm{C} 8$ position is a nodal point. Therefore, the substituents at the meso position are expected to alter the efficiency of the photoinduced electron transfer process (PET), but not intramolecular charge transfer (ICT). With this consideration, in the design of compound 2 (Scheme 1) the dipicolylamine ligand which is known to be selective for $\mathrm{Zn}(\mathrm{II})^{14 \mathrm{f}, 16}$ ions was placed at the 8-position (meso) of the Bodipy core. This is easily accomplished by the reaction of dipicolylamine-

(15) (a) Dost, Z.; Atilgan, S.; Akkaya, E. U. Tetrahedron 2006, 62, 84848488. (b) Rurack, K.; Trieflinger, C.; Koval'chuck, A.; Daub, J. Chem.-Eur. J. 2007, 13, 8998-9003. (c) Thivierge, C.; Bandichhore, R.; Burgess, K. Org. Lett. 2007, 9, 2135-2138. (d) Yuan, M.; Zhou, W.; Liu, X.; Zhu, M.; Li, J.; Yin, X.; Zheng, H.; Zuo, Z.; Ouyang, C.; Liu, H.; Li, Y.; Zhu, D. J. Org. Chem. 2008, 73, 5008-5014. (e) Li, L. L.; Han, J. Y.; Nguyen, B.; Burgess, K. J. Org. Chem. 2008, 73, 1963-1970. (f) Rohand, T.; Baruah, M.; Qin, W.; Boens, N.; Dehaen, W. Chem. Commun. 2006, 266-268. (g) Harriman, A.; Mallon, L.; Ziessel, R. Chem.-Eur. J. 2008, 14, 11461-11473. (h) Deniz, E.; Isbasar, G. C.; Bozdemir, O. A.; Yildirim, L. T.; Siemiarczuk, A.; Akkaya, E. U. Org. Lett. 2008, 10, 3401-3403. (i) Han, J. Y.; Gonzales, O.; Aguilar-Aguilar, A.; Pena-Cabrera, E.; Burgess, K. Org. Biomol. Chem. 2009, 7, 34-36. (j) Bozdemir, O. A.; Buyukcakir, O.; Akkaya, E. U. Chem.-Eur. J. 2009, 15, 3830-3838. (k) Yuan, M.; Yin, X.; Zheng, H.; Quyang, C.; Zuo, Z.; Liu, H.; Li, Y. Chem. Asian J. 2009, 4, 707-713. (1) Barin, G.; Yilmaz, M. D.; Akkaya, E. U. Tetrahedron Lett. 2009, 50, 1738-1740. (m) Erbas, S.; Gorgulu, A.; Kocakusakogullari, M.; Akkaya, E. U. Chem. Commun. 2009, 495, 6-4958. (n) Diring, S.; Puntoriero, F.; Nastasi, F.; Campagna, S.; Ziessel, R. J. Am. Chem. Soc. 2009, 131, 6108-6109. (o) Buyukcakir, O.; Bozdemir, O. A.; Kolemen, S.; Erbas, S.; Akkaya, E. U. Org. Lett. 2009, 11, 4644-4647.

(16) (a) Trokowski, R.; Ren, J.; Kalman, F. K.; Sherry, A. D. Angew. Chem., Int. Ed. 2005, 44, 6920-6923. (b) Wong, B. A.; Friedle, S.; Lippard, S. J. J. Am. Chem. Soc. 2009, 131, 7142-7152. (c) Xue, L.; Liu, C.; Jiang, H. Org. Lett. 2009, 11, 1655-1658.
Scheme 1. Synthesis of Target Compound 2
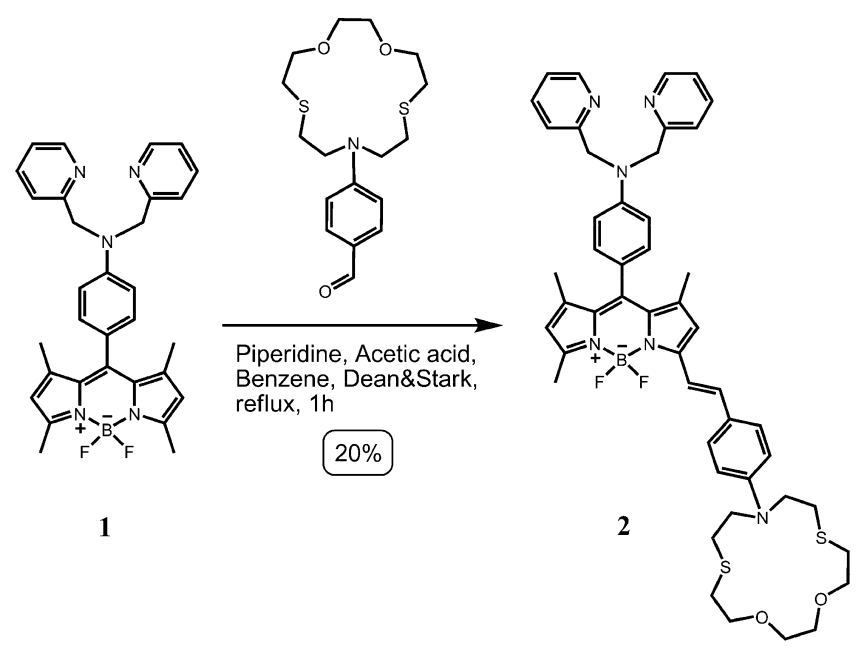

substituted benzaldehyde ${ }^{17}$ with 2,4-dimethylpyrrole under the usual conditions for Bodipy synthesis. The Bodipy dye $\mathbf{1}$ was then reacted with the known thiazacrown-tethered benzaldehyde $^{18}$ under Knoevenagel conditions, thus placing a strong ICT donor in full conjugation to the Bodipy core. The binucleating monostyryl-Bodipy (2) obtained in this way, was purified by column chromatography. The synthesis for the second target compound started with the known Bodipy dye, 4,4-difluoro-8phenyl-1,3,5,7-tetramethyl-4-bora-3a,4a-diaza-s-indacene. ${ }^{15 \mathrm{~h}}$ Consecutive Knoevenagel condensation reactions of the starting material with the two aromatic aldehydes mentioned above yielded first compound $\mathbf{3}$ and then $\mathbf{4}$ (Scheme 2). In this way, two ICT donors which can be modulated with two different metal ion modulators were installed on the fluorophore in full conjugation.

The synthetic pathway for the third target molecule 7 is shown in Scheme 3. Here, we start with a phenylazacrown-tethered meso-phenyl-Bodipy $\mathbf{5}$ where the phenylazacrown moiety is chosen as a PET modulator. The ICT modulators were then added one after the other, using thiaazacrown-benzaldehyde,

(17) Peng, X.; Du, J.; Fan, J.; Wang, J.; Wu, Y.; Zhao, J.; Sun, S.; Xu, T. J. Am. Chem. Soc. 2007, 129, 1500-1501.

(18) Ishikawa, J. Bull. Chem. Soc. Jpn. 1995, 68, 3071-3076. 
Scheme 2. Synthesis of Target Compound 4

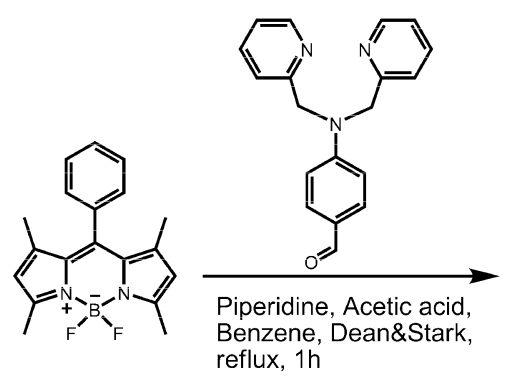

$24 \%$
3

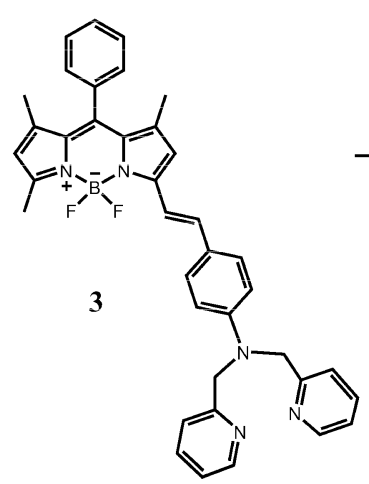

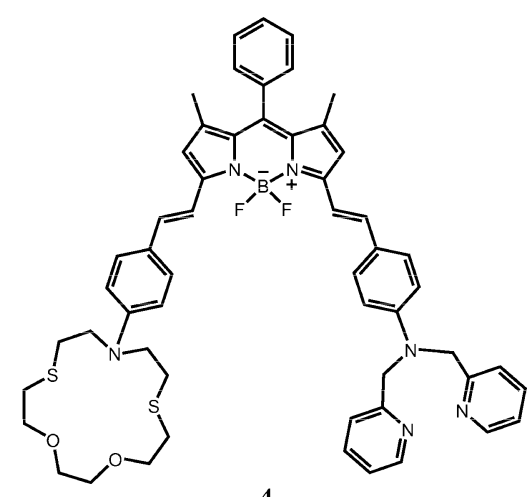

4

Scheme 3. Synthesis of Target Compound 7

5
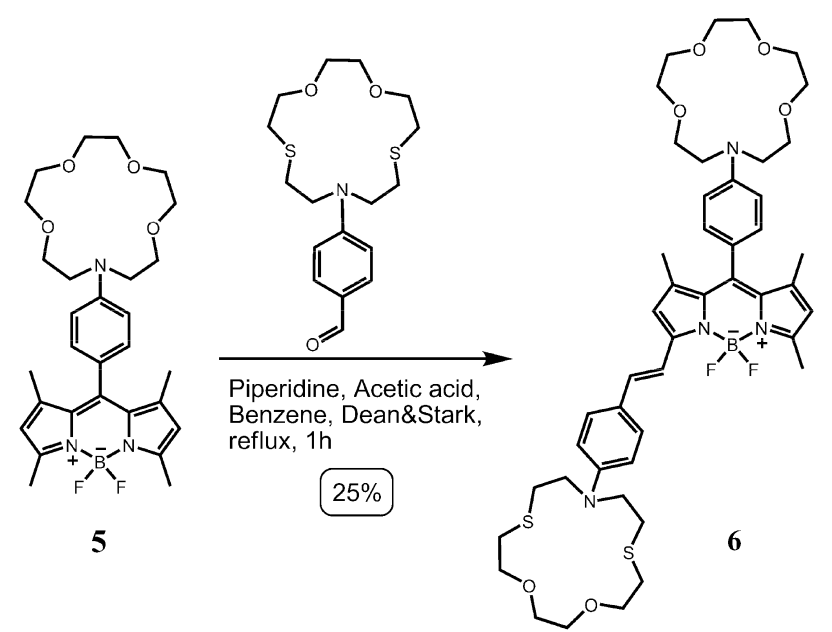

followed by dipicolylaminobenzaldehye, isolating the intermediate $\mathbf{6}$ during the two-step synthesis. The Knoevenagel condensations were driven by the continuous removal of the water formed using a Dean-Stark apparatus. Thus, compound 7 was obtained and purified by silica gel column chromatography. The azacrown
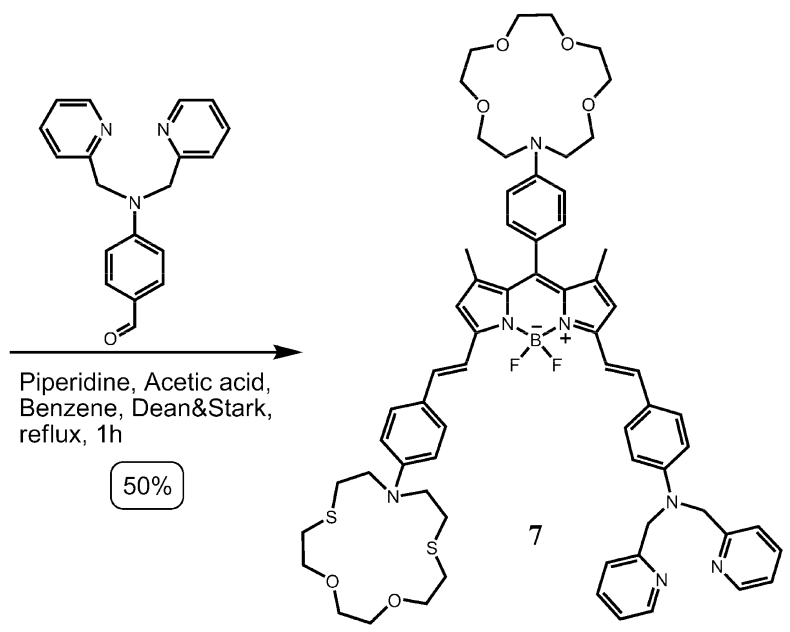

ether has a larger affinity for harder alkaline and alkaline-earth cations. ${ }^{19}$ The dithiaazacrown ligand is known to have a selectivity for $\mathrm{Hg}^{2+}$ over many other metal ions. ${ }^{14 \mathrm{j}}$ The dipicolylamine ligand is known to be highly selective for $\mathrm{Zn}$ (II) in many literature examples. Thus, three target molecules having

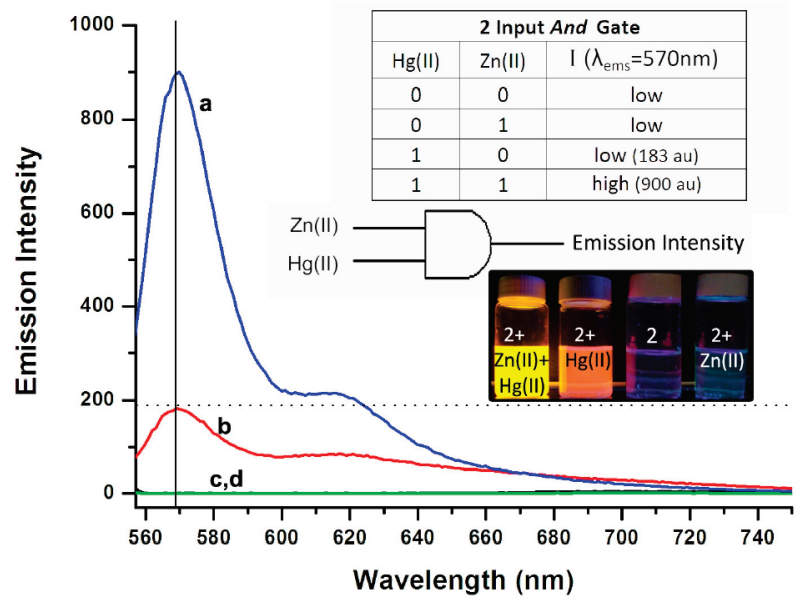

(a)
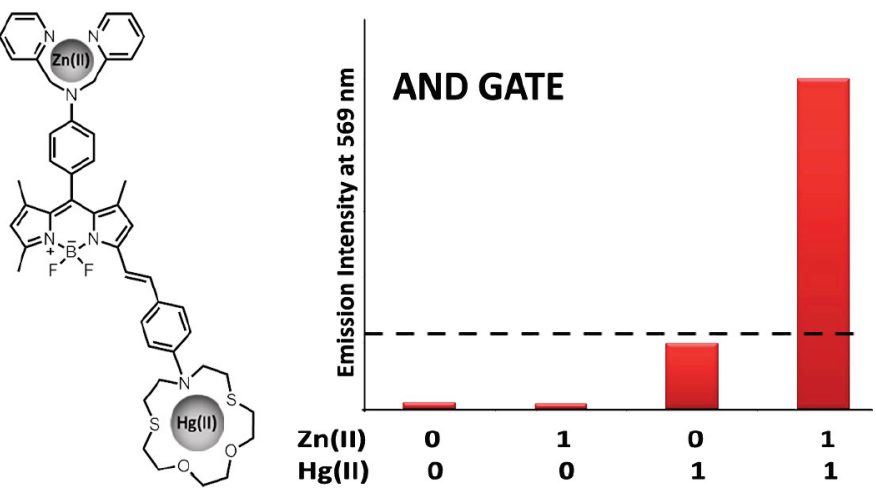

(b)

Figure 2. Emission spectra of $2(1.67 \mu \mathrm{M})$ in acetonitrile in the presence of $\mathrm{Hg}(\mathrm{II})$ and $\mathrm{Zn}$ (II) $(6.68$ and $1.67 \mu \mathrm{M}$, respectively). Inset shows truth table for AND gate $\left(\lambda_{\mathrm{ex}}=555 \mathrm{~nm}\right)$. 


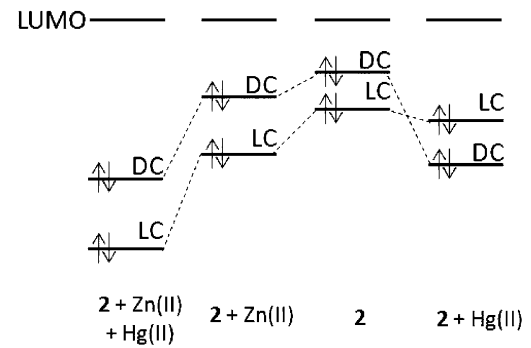

Figure 3. Qualitative assessment of relative energy levels of frontier molecular orbitals in metal ion-2 interactions. DC refers to dye (2) centered molecular orbitals confined essentially to the Bodipy core. LC refers to the ligand centered orbitals which are potential electron donors at the excited state. These are invariably located at the meso-tethered dipicolylamine unit. LUMOs were adjusted arbitrarily to the same level for clarity. See Supporting Information for further details on computational work.

ligands of different affinities, organized in diverse arrangements, were synthesized.

\section{Results and Discussion}

Precise Control of PET and ICT Processes. The emission spectra of binucleating monostyryl-Bodipy $\mathbf{2}$ in the presence of added metal ion modulators are shown in Figure 2. The emission spectrum of the dye has a broad peak, with a maximum at $679 \mathrm{~nm}$. It is interesting to note that the addition of $\mathrm{Zn}$ (II) ions in the form of a perchlorate salt has a minimal effect with very small changes in the emission intensity or peak maximum; apparently the ICT donor dialkylaminophenyl group in full conjugation with the Bodipy core determines the spectrum, since $\mathrm{Zn}$ (II) at the applied concentration $(1.67 \mu \mathrm{M})$ has a much lower affinity for the thiazacrown moiety and charge transfer is not altered to any extent. In addition, PET is known to be less significant in the longer wavelength region of the spectrum (vide infra). On the other hand, the addition of $\mathrm{Hg}$ (II) $(6.68 \mu \mathrm{M})$ alone leads to an entirely different outcome: the softer $\mathrm{Hg}(\mathrm{II})$ ions prefer the thiaazacrown ligand, causing a blue shift of $109 \mathrm{~nm}$. This is due to a reduced charge transfer on metal ion binding, increasing the HOMO-LUMO gap. However, PET from the meso substituent becomes more pronounced, since $\mathrm{Hg}^{2+}$ does not have a particularly high affinity for the azacrown; thus the emission intensity at the peak $(570 \mathrm{~nm})$ stays low. When both ions were added at the concentrations above, finally the PET from the dipicolylamine substituent is blocked and also the large spectral shift; we now have an impressive enhancement of emission at $570 \mathrm{~nm}$. The inset picture shows the colorful signaling which is in accordance with the AND logic when the emission is recorded at $570 \mathrm{~nm}$. The experimental results obtained here is in accordance with a theoretical model for a Bodipy system with both PET and ICT active groups. MO calculations for compound 2 at the DFT (B3LYP/6-31G) level reveal a number of frontier orbitals centered at the fluorophore or ligand(s), and using these data and protonation of the donor amino nitrogen as a reasonable model for metal ion binding, the following MO description of the signals can be obtained (Figure 3): (i) The major transition is always from the Bodipy centered orbital (HOMO or HOMO-1) to the LUMO, which is again invariably dye centered (DC in Figure 3). (ii) PET activity is linked to the presence of a ligand centered HOMO (here ligand refers specifically to the dipicolylamine ligand) above a dye-centered orbital, to the energy gap between this HOMO orbital and the dye-centered HOMO -1 . The magnitude of this gap is related to the thermodynamic driving force for PET and thus the rate of PET. PET is nonexistent or slow for compound $\mathbf{2}$ alone. However, the emission is still low due to a polar excited state, since the measurements were performed in a polar solvent. In addition, nonradiative decay is faster for longer wavelength transitions. When $\mathrm{Hg}$ (II) is added, since it is highly selective for the thiaazacrown unit, but not the dipicolyamine ligand, thus the energy level of the potential PET donor is not significantly affected. The dye centered orbital is now HOMO, and it will be an efficient PET donor. This is why when $\mathrm{Hg}$ (II) ions were added, there is a blue shift, but no increase in the emission intensity. In a 1:1 complex of $\mathbf{2}-\mathrm{Hg}$ (II), PET is expected to be more effective. When only $\mathrm{Zn}(\mathrm{II})$ ions were added, the relative positions of the dye centered HOMO and the ligand centered LUMO are not changed, but the ligand centered orbital is highly stabilized. This actually translates as little or no change in the emission character as the HOMOLUMO gap is moderately affected. But when both ions were added, the stabilizion of dye centered HOMO (larger gap for the major transition) and the large stabilization of the ligand-

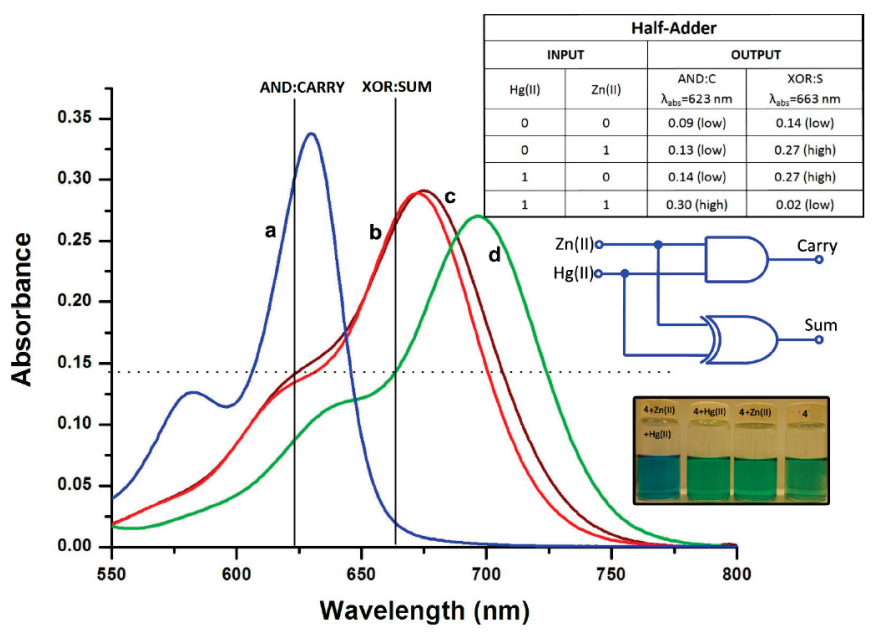

(a)
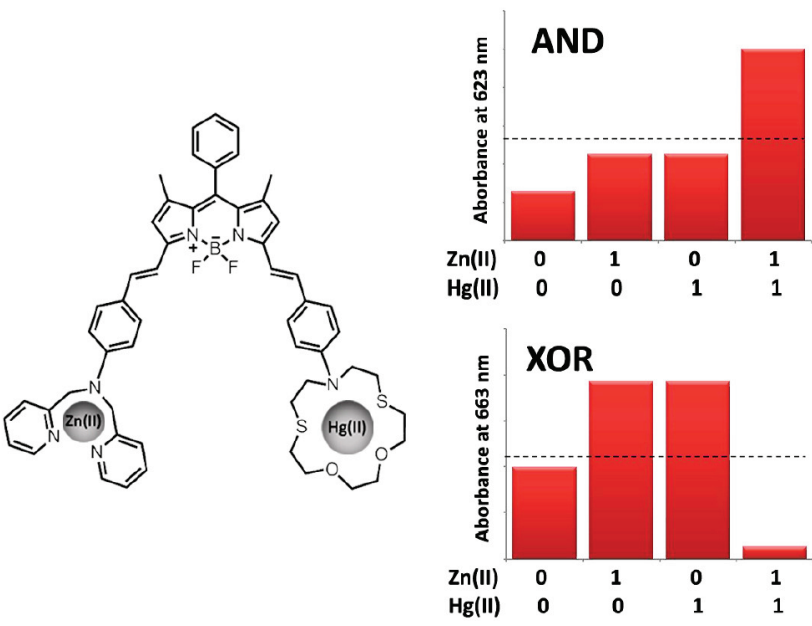

(b)

Figure 4. Absorption spectra of compound $4(3.2 \mu \mathrm{M})$ in acetonitrile in the presence of $\mathrm{Hg}(\mathrm{II})$ and $\mathrm{Zn}$ (II) ions ( 28.8 and $32.0 \mu \mathrm{M}$, respectively). Inset shows truth table for half-adder. 
Table 1. Spectroscopic Data for Compounds 2, 4, 5, 7, and Their Metal Complexes

\begin{tabular}{lccrrr}
\hline \multicolumn{1}{c}{ compds } & $\begin{array}{c}\lambda_{\max } \\
(\mathrm{nm})\end{array}$ & $\begin{array}{c}\text { Abs } \\
(\mathrm{nm})^{a}\end{array}$ & $\begin{array}{c}\varepsilon_{\max } \\
\left(\mathrm{M}^{-1} \mathrm{~cm}^{-1}\right)\end{array}$ & $\begin{array}{r}\text { fwhm } \\
\left(\mathrm{cm}^{-1}\right)\end{array}$ & $\kappa^{b}$ \\
\hline $\mathbf{2}$ & 600 & 0.135 & 80000 & 1540 & 0.10 \\
$\mathbf{2}+\mathrm{Zn}(\mathrm{II})$ & 602 & 0.132 & 79000 & 1640 & 0.16 \\
$\mathbf{2}+\mathrm{Hg}(\mathrm{II})$ & 560 & 0.075 & 53000 & 2460 & 0.19 \\
$\mathbf{2}+\mathrm{Zn}(\mathrm{II})+\mathrm{Hg}(\mathrm{II})$ & 560 & 0.153 & 92000 & 900 & 0.43 \\
$\mathbf{4}$ & 697 & 0.259 & 81000 & 1420 & 0.11 \\
$\mathbf{4}+\mathrm{Zn}(\mathrm{II})$ & 673 & 0.288 & 90000 & 1440 & 0.33 \\
$\mathbf{4}+\mathrm{Hg}(\mathrm{II})$ & 674 & 0.294 & 92000 & 1640 & 0.28 \\
$\mathbf{4}+\mathrm{Zn}(\mathrm{II})+\mathrm{Hg}(\mathrm{II})$ & 630 & 0.34 & 106000 & 840 & 0.78 \\
$\mathbf{5}$ & 497 & 0.101 & 60600 & 960 & 0.012 \\
$\mathbf{5}+\mathrm{Ca}(\mathrm{II})$ & 498 & 0.095 & 57000 & 870 & 0.592 \\
$\mathbf{7}$ & 692 & 0.142 & 71000 & 1280 & 0.038 \\
$\mathbf{7}+\mathrm{Ca}(\mathrm{II})+\mathrm{Zn}(\mathrm{II})+\mathrm{Hg}(\mathrm{II})$ & 626 & 0.122 & 61000 & 1240 & 0.266 \\
& & & & &
\end{tabular}

${ }^{a}$ Peak absorption values at the specific concentrations of the study. ${ }^{b}$ Quantum yields for compounds 2, 4, and $\mathbf{7}$ were determined in reference to Sulforhodamine 101 (0.90 in ethanol), and for compound $\mathbf{5}$ Rhodamine 6G (0.95 in ethanol) was used as a reference.

centered (dipicolyamine) orbitals (blocking of PET) were in effect. The net result is a blue shift with a significant increase in the emission intensity.

Half-Adder in the Absorption Mode. The distyryl compound 4, on the other hand, have two different ligands attached to the Bodipy core as ICT donors. The spectral changes are the direct consequences of relative affinities of these ligands to $\mathrm{Hg}$ (II) $)^{14 \mathrm{e}}$ and $\mathrm{Zn}(\mathrm{II}){ }^{14 \mathrm{f}, 20} \mathrm{~A}$ dilute solution $(3.2 \mu \mathrm{M})$ of the distyrylBodipy dye 4 in acetonitrile has an absorbance peak at $698 \mathrm{~nm}$ (Figure 4). When $\mathrm{Zn}$ (II) ions were added in the form of perchlorate salt, there is a small blue shift to $675 \mathrm{~nm}$. A similar shift takes place when $\mathrm{Hg}$ (II) alone was added. It is clear that even an excess of these ions target essentially just one of the ligands, thus blocking ICT only partially. However, when both ions were added, the peak shifts further toward shorter wavelengths, the new metal-bound complex absorbs maximally at $630 \mathrm{~nm}$. When the absorbance is recorded at $623 \mathrm{~nm}$, the data are in accordance with AND logic. Absorbance data collected near the longer wavelength peak, however, result in an XOR logic. When these two gates are operated in parallel, a half-adder is obtained. The relevant spectra and the truth table for the two logic gates are shown Figure 4.
Three-Input AND Gate. An absorption spectrum of the ternucleating (tritopic) compound 7 is presented in the Supporting Information, and the effects of added metal ions $\left(\mathrm{Ca}^{2+}\right.$, $\mathrm{Zn}^{2+}$ and $\mathrm{Hg}^{2+}$ ) are apparent. The spectral data for all three target compounds and their metal complexes were tabulated in Table 1. It is clear that the metal ions separately or together have different affinities (or regioselectivities). Harder $\mathrm{Ca}$ (II) ions prefer to interact with the harder azacrown ligand at the meso position of the Bodipy dye. This interaction is not expected to alter the absorption spectrum, but since it has to be added at a larger concentration $(1.0 \mathrm{mM})$ than the other metal ions, a minor $25 \mathrm{~nm}$ blue shift is nevertheless observed, indicating some interference at the ICT donor ligands. Compared to a free fluoroionophore, an approximately $25 \mathrm{~nm}$ blue shift was observed in the following combinations: $\mathrm{Ca}(\mathrm{II}), \mathrm{Zn}(\mathrm{II})$, $\mathrm{Ca}(\mathrm{II})+\mathrm{Zn}$ (II). $\mathrm{Hg}$ (II) is particularly effective, and in all input scenarios including $\mathrm{Hg}(\mathrm{II})$, there is a large $70 \mathrm{~nm}$ hypsochromic shift. Nevertheless, it is obvious that absorbance changes seem far too complicated to be of much use in logic gate design. However, the emission changes (Figure 5) result in a better picture for this purpose. At the concentrations used in the present work $(\mathrm{Hg}(\mathrm{II})$ and $\mathrm{Zn}(\mathrm{II})$ at $20.0 \mu \mathrm{M}$ and $\mathrm{Ca}(\mathrm{II})$ at $1.0 \mathrm{mM}$ ), only when all three cations were added as inputs, emission is significantly enhanced above the threshold. The three cations separately, or in other binary combinations, do not induce an enhanced and blue-shifted emission from compound 7. Thus, all three metal ion inputs are required simultaneously for the large emission increase at $656 \mathrm{~nm}$; this behavior is in accordance with an AND logic gate. One can envision a scenario where elevated concentrations of three different molecular or ionic species may indicate a particular disease state (lab-on-a molecule, as elaborated previously by de Silva); thus a nonzero AND logic response could be a positive identification of that particular state. The use of multiple photophysical processes for eliciting an AND response is highly relevant, as it would minimize false positives, since for example, in this case, both a blue shift and large enhancement of the emission signal should be expected. In addition, simultaneous sensing is also possible: PET and ICT processes can clearly be addressed separately; for shorter wavelength emitting fluorophores, PET processes can be effective, and be separately blocked by an appropriate

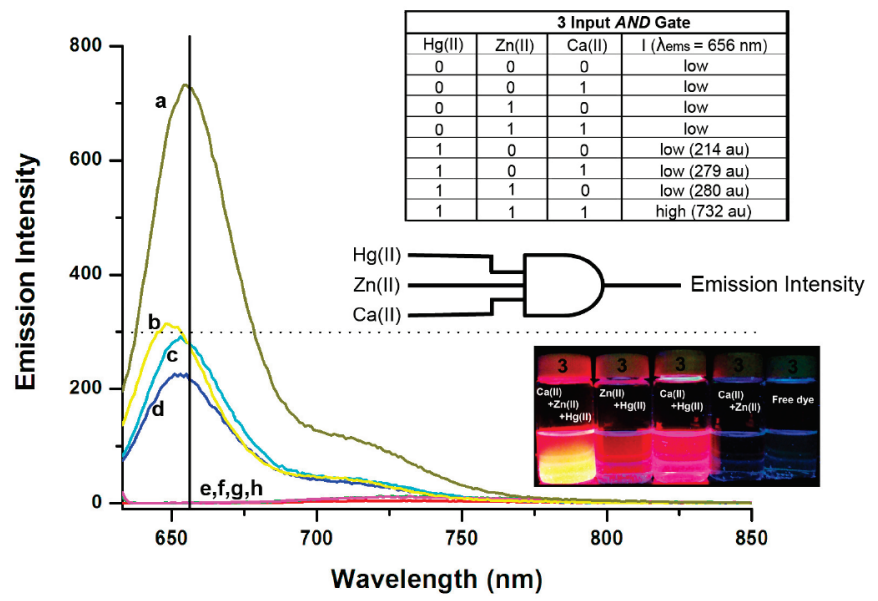

(a)

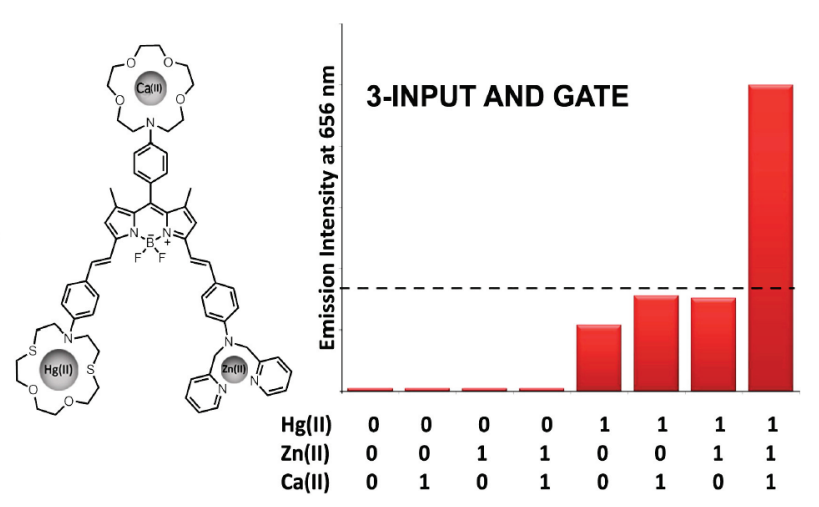

(b)

Figure 5. Emission spectra of $7(2.0 \mu \mathrm{M})$ in acetonitrile in the presence of $\mathrm{Hg}(\mathrm{II}), \mathrm{Zn}(\mathrm{II})$, and $\mathrm{Ca}(\mathrm{II})(20.0 \mu \mathrm{M}, 20.0 \mu \mathrm{M}$, and $1.0 \mathrm{mM}$ respectively). Inset shows truth table for 7 input AND gate $\left(\lambda_{\mathrm{ex}}=630 \mathrm{~nm}\right.$ ). a: $7+\mathrm{Ca}(\mathrm{II})+\mathrm{Zn}(\mathrm{II})+\mathrm{Hg}(\mathrm{II})$ b: $7+\mathrm{Ca}(\mathrm{II})+\mathrm{Hg}$ (II) c: $7+\mathrm{Zn}$ (II) $+\mathrm{Hg}$ (II) $\mathrm{d}: \mathbf{7}+\mathrm{Hg}$ (II) e: 7 f: 7+Ca(II) $+\mathrm{Zn}$ (II) g: 7+Ca(II) h: 7+Zn(II). Excitation wavelength is $620 \mathrm{~nm}$. 
Table 2. Binding Constants Determined by Isothermal Titration Calorimetry (ITC) for the Relevant Binding Events

\begin{tabular}{|c|c|c|c|c|}
\hline titration & $\begin{array}{c}K \\
\left(M^{-1}\right)\end{array}$ & $\underset{(\mathrm{kcal} / \mathrm{mol})}{\Delta H}$ & $\begin{array}{c}\Delta S \\
\mathrm{cal} /(\mathrm{mol} \cdot \mathrm{K})\end{array}$ & model \\
\hline $\begin{array}{l}\text { Compound } 1 \\
\text { (1:1) binding-Zn(II) }\end{array}$ & $(4.8 \pm 0.4) \times 10^{7}$ & $-7.5 \pm 1.6$ & 5.99 & two sets of sites \\
\hline $\begin{array}{l}\text { Reference }^{b} \\
\text { dithiaazacrown-Hg(II) }\end{array}$ & $(3.4 \pm 0.8) \times 10^{6}$ & $-11.6 \pm 0.08$ & -9.27 & one set of sites \\
\hline Compound $1-\mathrm{Hg}(\mathrm{II})$ & $(9.1 \pm 0.5) \times 10^{6}$ & $-15.3 \pm 0.02$ & -19.3 & one set of sites \\
\hline $\begin{array}{l}\text { Half adder } 4-\mathrm{Hg}(\mathrm{II}) \text {, } \\
\text { second binding }\end{array}$ & $(1.1 \pm 0.2) \times 10^{5}$ & $-1.1 \pm 0.2$ & -41.1 & two sets of sites \\
\hline AND gate $2-Z n(I I)$ & $(1.8 \pm 0.8) \times 10^{6}$ & $-6.8 \pm 0.2$ & 5.7 & one set of sites \\
\hline AND gate $2-\mathrm{Hg}(\mathrm{II})$ & $(1.3 \pm 0.9) \times 10^{8}$ & $-12.0 \pm 0.1$ & -3.18 & two sets of sites \\
\hline $\begin{array}{l}\text { AND gate } 2-\mathrm{Hg}(\mathrm{II}) \text {, } \\
\text { second binding }\end{array}$ & $(7.7 \pm 1.2) \times 10^{4}$ & $-8.1 \pm 0.2$ & -4.74 & two sets of sites \\
\hline
\end{tabular}

${ }^{a}$ Compound 1 shows a clear 1:2 (two Bodipy-ligands-one Zn(II)) interaction at high concentrations of 1. Similar interaction is not observed when the dipicolylamine ligand is tethered with a styryl group to the 3 (or 5) position of Bodipy, which can be understood in terms of steric demands of a 1:2 interaction. ${ }^{b}$ The reference compound used here is $N$-(4-formylphenyl)-1-aza-4,13-dithia-[15]crown-5.
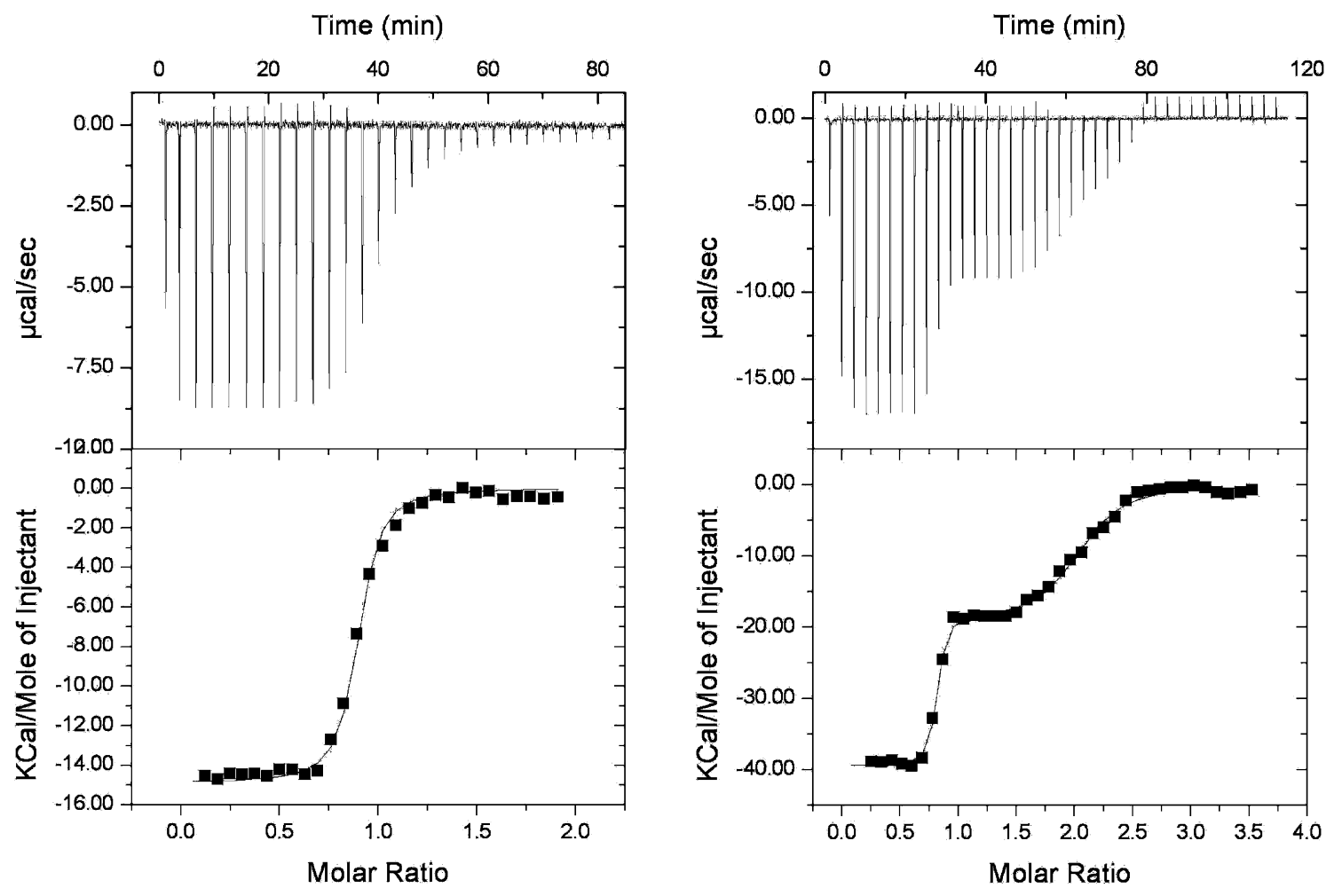

Figure 6. ITC titration curves of compound 4 in acetonitrile. Left: $0.4 \mathrm{mM} 4$ titrated with $5.0 \mathrm{mM} \mathrm{Zn}\left(\mathrm{ClO}_{4}\right)_{2}$, Right: $0.3 \mathrm{mM} 4$ titrated with $5.0 \mathrm{mM}$ $\mathrm{Hg}\left(\mathrm{ClO}_{4}\right)_{2}$.

metal ion, resulting signal enhancement, regardless of the ICT modulating ions. On the other hand, the ICT donor ligand will result in a spectral shift which can be correlated to the concentration of the analyte targeting that particular ligand.

Binding Constants. Isothermal titration calorimetry was useful in determining the binding constants of $\mathrm{Hg}$ (II) and $\mathrm{Zn}$ (II) (Table 2). Experimentally determined binding affinities confirm the

(19) (a) Das, S.; Thomas, K. G.; Thomas, K. J.; Kamat, P. V.; George, M. V. J. Phys. Chem. 1994, 98, 9291-9296. (b) Martin, M. M.; Plaza, P.; Meyer, Y. H.; Badaoui, F.; Bourson, J.; Lefebvre, J. P.; Valeur, B. J. Phys. Chem. 1996, 100, 6879-6888. (c) Vladimirova, M. P.; Simova, S. D.; Stanoeva, E. R.; Mitewa, M. I. Dyes Pigm. 2001, 50, $157-162$.

(20) Connors, K. A. Binding Constants: The Measurement of Molecular Complex Stability; John Wiley \& Sons: New York, 1987. working principle of the proposed molecular logic gates. For example, half-adder molecule 4 when titrated with $\mathrm{Zn}$ (II) ions shows just one binding, indicating an affinity for the picolylamine ligand, but not for the dithiaazacrown ligand (Figure 6). The two-input AND logic titration with $\mathrm{Zn}$ (II) ions also shows just one binding event. Compared to that of $\mathrm{Hg}$ (II) ions, the larger affinity of $\mathrm{Zn}(\mathrm{II})$ ions for the dipicolylamine ligand is apparent in the separate titration studies (Figure 7) done with these two cations and the reference compound $1\left(4.8 \times 10^{7}\right.$ $\mathrm{M}^{-1}$ for $\mathrm{Zn}(\mathrm{II})$ and $9.1 \times 10^{6} \mathrm{M}^{-1}$ for $\left.\mathrm{Hg}(\mathrm{II})\right)$. Titration of ditopic compounds with $\mathrm{Hg}$ (II) ions revealed that $\mathrm{Hg}$ (II) ions have strong affinities for both dipicolylamine and the dithiaazacrown ligands, and at larger concentrations both ligands would be engaged. But at the selected concentrations of $\mathrm{Zn}$ (II) and 

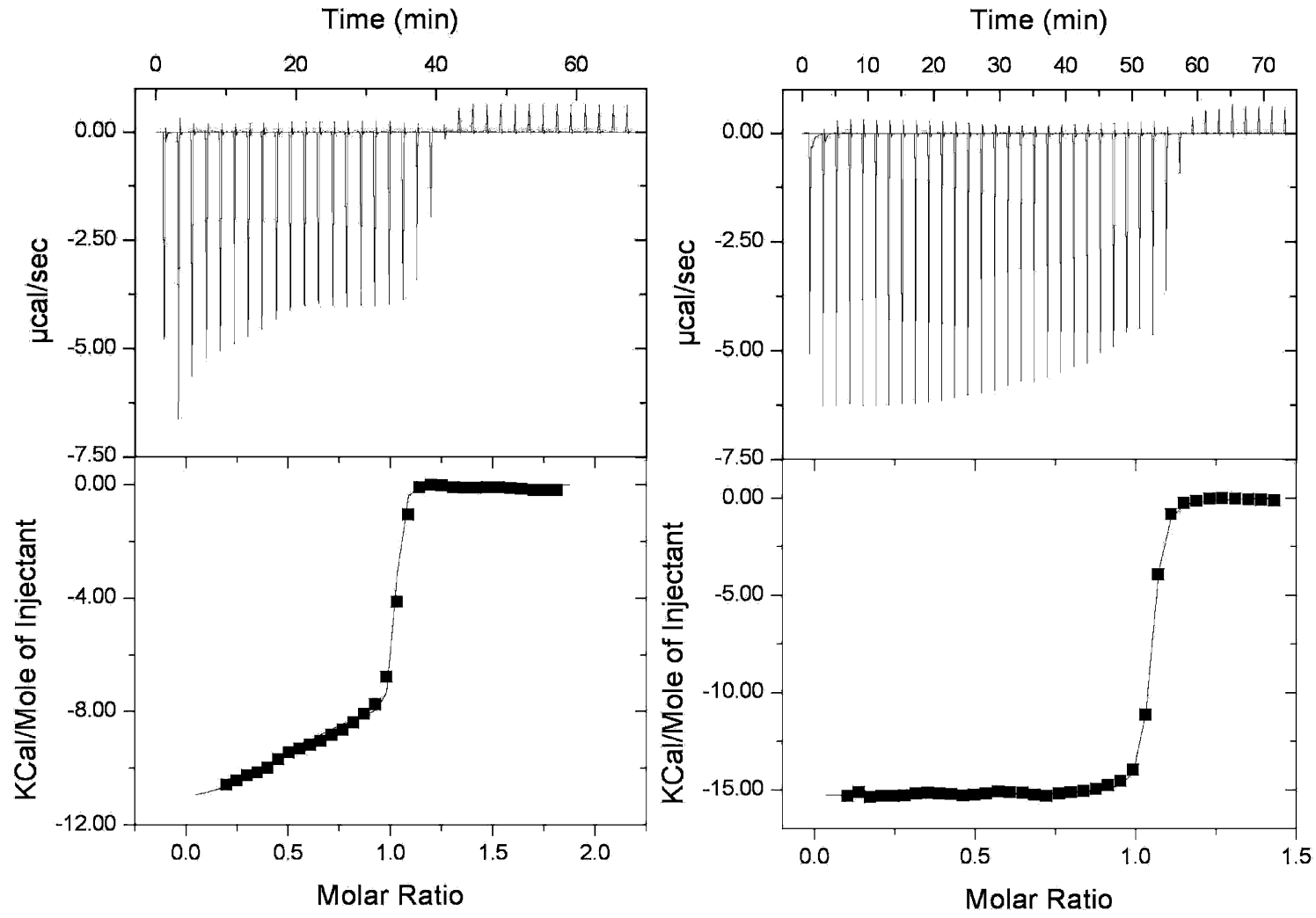

Figure 7. ITC titration curves of reference compound 1 in acetonitrile. Left: $0.5 \mathrm{mM} 1$ titrated with $5.0 \mathrm{mM} \mathrm{Zn}\left(\mathrm{ClO}_{4}\right)_{2}$, Right: $0.5 \mathrm{mM} 1$ titrated with 4.0 $\mathrm{mM} \mathrm{Hg}\left(\mathrm{ClO}_{4}\right)_{2}$.

$\mathrm{Hg}(\mathrm{II})$ as inputs, the dynamic nature of the binding events dictates that $\mathrm{Zn}(\mathrm{II})$ ions with no affinity for the dithiaazacrown ligand and a larger affinity for the dipicolyl ligand will preferentially occupy the dpa ligand. This order of affinity will be in place for all three logic gates designs. On the other hand, the binding affinity of $\mathrm{Ca}$ (II) ions was significantly smaller; therefore the relavant binding constant in the interaction of these ions with three-input logic gate molecule 7 was determined by spectrofluorometry. The value obtained for $K$ is $680 \mathrm{M}^{-1}$ (Supporting Information) suggesting that, at higher input concentrations of $\mathrm{Ca}(\mathrm{II})$ ions, the crown ether moiety will be engaged by this cation.

\section{Conclusion}

We demonstrated that, with prior knowledge of respective binding affinities of metal ions for various ligands, it should be possible to design molecular logic gates using different metal ions as inputs. Bodipy chemistry is particularly useful in this regard, because it allows straightforward placement of ICT and PET donors on the same molecule, which increases signal diversity to a great extent. Styryl modifications of Bodipy proved to be a useful reaction. In the three examples presented, this modification allowed us to place ICT donor functionalities at strategically important positions. The result is straightforward syntheses of the target molecules, with responses compatible with AND logic, and a molecular half-adder with nonannihilating inputs. Outputs compatible with XOR logic have been difficult to attain without the use of self-annihilating (such as acids and bases, either Lewis or Bronsted-Lowry) inputs, but in the half-adder described in this work, this is done by the differential selective interactions between the ligands and the metal ions selected. Using signals obtained by exploiting the relative selectivity of inputs for different ligands/chelators, more challenging molecular logic operations should be within reach.

Acknowledgment. The authors gratefully acknowledge support from TUBA (Turkish Academy of Sciences). We also thank Prof. Talat Yalcin and Mr. Cagdas Tasoglu (both of IYTE, Chemistry Department, Izmir) for the mass spectrometry measurements and Ms. Merve Turksanli for guidance in ITC experiments. R.G. and S.S. thank TUBITAK for scholarships.

Supporting Information Available: Synthesis procedures for the new compounds, ${ }^{1} \mathrm{H}$ and ${ }^{13} \mathrm{C}$ NMR spectra, additional absorbance and emission spectra, mass spectra, isothermal titration and computational data. This material is available free of charge via the Internet at http://pubs.acs.org.

JA1008163 